Newcombe, H. B. (1953). J. gen. Microbiol. 9, 30-36.

\title{
Radiation-induced Instabilities in Streptomyces
}

\author{
BY H. B. NEWCOMBE \\ Atomic Energy of Canada Limited, Chalk River, Ontario, Canada
}

\begin{abstract}
SUMMARY : A variety of heritable changes affecting colony morphology and colour are induced in a Streptomyces sp. by exposure of the spores to ultraviolet and gamma rays. Most of the changes are associated with instabilities which give rise to further variation during colony growth and spore formation. The instabilities persist indefinitely in most lines of descent and give rise to characteristic proportions of new variant types each having its own pattern of instability. The ultraviolet dose/effect curve shows the familiar peak and decline found for mutations in many other organisms. The present changes, however, differ from the gene mutations previously studied in that they can be induced with much greater frequencies $(30-60 \%$ of the colonies being affected), and that gamma rays are as effective or more so than ultraviolet irradiation. This suggests that the initial changes, and perhaps subsequent ones as well, might be more of the nature of the chromosomal rearrangements, rather than of the gene mutations, of higher organisms. Similar instabilities arise spontaneously but with a much lower frequency.
\end{abstract}

Studies of sectoring for induced mutations in the colonies from irradiated bacteria have been complicated by the lack of precise information as to the number of nuclei in the irradiated cells (Newcombe, 1951, 1953; Witkin, $1951 a, b)$. To avoid this difficulty an actinomycete, the spores of which were known to be uninucleate (J. McGregor, unpublished; see also KlienebergerNobel, 1947), was chosen for the further study of induced sectoring.

It is known that ultraviolet- and gamma-irradiated actinomycete spores yield high proportions of mutant colonies, and that some of the changes occur as sectors (Kelner, 1948, 1949), but the sectoring phenomenon had not been studied in any detail. The present observations show that the spontaneous and induced mutations occurring in the actinomycetes have a very different behaviour from those studied previously in the bacteria.

\section{Materials and methods}

A strain of Streptomyces sp. was supplied by Dr J. W. Rouatt (his strain T12), the colonies of which have a deep orange-coloured base covered with a fluffy layer of paler orange aerial mycelium. All platings were on a medium composed of: asparagine, 0.05 ; peptone, $0.05 ; \mathrm{K}_{2} \mathrm{HPO}_{4} .3 \mathrm{H}_{2} \mathrm{O}, 0.05$; glucose, 1.0 ; agar, $1.5($ as $\%, w / v)$. Spore suspensions were prepared by flooding the confluent growth on agar with normal saline ( $(0.85 \%)$, scraping and agitating to loosen the spores, decanting, blending for $30 \mathrm{sec}$, and filtering through No. 2 Whatman filter-paper to remove any pieces of aerial mycelium. Suspensions could be stored in the cold for a month or more with very little loss of viability.

The treatments were carried out with gamma rays from Cobalt 60 (administered at the rate of $5000 \mathrm{r}$./hr.) and with ultraviolet irradiation by a G.E. 
Germicidal lamp. In the case of the ultraviolet irradiation $10 \mathrm{ml}$. of spore suspension were exposed in a $10 \mathrm{~cm}$. diameter Petri dish, with continuous agitation. The dose of gamma radiation was determined chemically (using a ferrous salt system), and ultraviolet dose by means of a Westinghouse dose-meter.

\section{Types of change}

Changes involving loss of aerial mycelium were classed as: crinkled (an uneven decrease giving the colony a dimpled appearance at the centre with narrow radial valleys reaching to the edge); stubble (incomplete loss); and roaxy (complete loss). Losses of the orange pigment of the base resulted in either a yellow or a white colour. Areas with altered aerial mycelium often had altered colour as well. Each of the above categories contained a wide range of types differing from one another in such minor properties as tint and texture of the aerial mycelium, and its distribution over the surface of the colony. Of the stubbles, for example, some had a darker orange and some a paler orange stubbling; the density of the stubbling was sometimes greatest at the centre, sometimes greatest at the periphery, and sometimes uniform.

The above categories of apparent losses include all but the rarer changes, such as those to a smaller colony size (minute) or to a pink or red base, together with some alterations of the texture and shade of the aerial mycelium which were too slight to be scored with accuracy. Peripheral sectors which obviously arose during the growth of otherwise normal colonies were not scored.

Sectoring of a colony for two or more types of change, or for different degrees of the same change, was common both with ultraviolet and with gamma irradiation (see Table 1), but sectors of normal appearance were

Table 1. Multiplicity of sectoring in colonies from irradiated spores

\begin{tabular}{|c|c|c|c|c|}
\hline \multirow{3}{*}{$\begin{array}{l}\text { No. of types of growth } \\
\text { in a single colony }\end{array}$} & \multicolumn{4}{|c|}{ No. of colonies } \\
\hline & \multicolumn{2}{|c|}{$\begin{array}{c}\text { Gamma* treated } \\
\text { Colonies }\end{array}$} & \multicolumn{2}{|c|}{$\begin{array}{c}\text { Ultraviolet } \dagger \text { treated } \\
\text { Colonies }\end{array}$} \\
\hline & No. & $\%$ & No. & $\%$ \\
\hline One (normal) & 1158 & $69 \cdot 3$ & 927 & $83 \cdot 1$ \\
\hline One (mutant) & 142 & $8 \cdot 5$ & 82 & $7 \cdot 4$ \\
\hline Two & 225 & $13 \cdot 4$ & 58 & $5 \cdot 2$ \\
\hline Three & 114 & $6 \cdot 8$ & 44 & $3 \cdot 9$ \\
\hline Four & $\mathbf{3 3}$ & $\mathbf{2} \cdot \mathbf{0}$ & 4 & $0 \cdot 4$ \\
\hline Total colonies & 1672 & - & 1115 & - \\
\hline Mutant colonies & 514 & - & 188 & - \\
\hline
\end{tabular}

* 50,000 r; survival approx. 0.1\%.

$\dagger$ Combined data from 1000 and 2000 ergs/sq.mm.; survivals approx. 0.017 and 0.006\%.

relatively infrequent $(17 \cdot 7 \%$ of the 514 gamma-induced mutants had sectors which looked normal) and almost all yielded spores which developed into variant colonies. (For examples of the colony types see Pl. 1, figs. 1-5.) 


\section{Instability}

Since the irradiated spores were known to be uninucleate and free from appreciable clumping (as indicated by direct observation and by the extreme rarity of genuine normal sectors) the multiplicity of sectoring must indicate some instability during colony growth. A further and apparently greater instability during spore formation was indicated by the range of variant colony types which grew from spores of the morphologically normal sectors, and also from those of the crinkled and stubble areas:

Sectoring. Early changes must be assumed to have occurred in some of the colonies where the sectors were regular and extended to the centre. Prolonged instabilities seem, however, to have been common since shallow sectors of stubble and waxy were frequent, and were often surrounded by the crinkled type from which they appeared to have arisen. Yellow (and white) appeared sometimes to have been derived in turn from stubble and waxy, and sometimes directly from crinkled.

Further support for the concept of crinkled as a category of primary unstable types was provided by: (1) its high frequency of occurrence (all but $23 \%$ of the gamma-induced mutant colonies had crinkled areas); (2) its appearance of inhomogeneity; (3) the tendency for the other categories of change to occur preferentially in colonies with crinkled areas (see Table 2).

Table 2. Correlated occurrence of crinkled in the same colony with other types of change

Dose of gamma radiation $50,000 \mathrm{r}$.

\begin{tabular}{|c|c|c|c|c|}
\hline \multirow{3}{*}{$\begin{array}{l}\text { Types of variants } \\
\text { (other than crinkled) }\end{array}$} & \multicolumn{4}{|c|}{ Colonies } \\
\hline & \multicolumn{2}{|c|}{ Without crinkled areas } & \multicolumn{2}{|c|}{ With crinkled areas } \\
\hline & No. & $\% *$ & No. & $\% \dagger$ \\
\hline No other type & 1158 & - & 136 & - \\
\hline Aerial mycelium only & 83 & $6 \cdot 5$ & 118 & $29 \cdot 7$ \\
\hline Colour only\& & 7 & $0 \cdot 6$ & 17 & $4 \cdot 3$ \\
\hline Aerial mycelium and colour $\|$ & 27 & $\mathbf{2 \cdot 2}$ & 126 & $31 \cdot 7$ \\
\hline \multicolumn{5}{|c|}{$\begin{array}{l}\text { * Of colonies without crinkled. } \\
\dagger \text { Of colonies with crinkled. } \\
\ddagger \text { Stubble or waxy. } \\
\$ \text { White or yellow. } \\
\text { II In the same colony, not necessarily the same sector. }\end{array}$} \\
\hline
\end{tabular}

The concept of stubble and waxy as secondary unstable types from which an appreciable proportion of the changes to yellow and white were derived is supported by the frequencies with which the yellow and white areas were themselves stubble or waxy, and with which they occurred together in the same colony with stubble or waxy areas of normal colour (see Table 3). It seems probable that there are many primary unstable states giving rise to variant sectors and spores, and that these variants are themselves unstable, and so on indefinitely. Certainly this was true of the instabilities which became apparent during spore formation. 
Table 3. Correlated occurrence of colour variations with stubble and waxy

Dose of gamma radiation 50,000 r.

\begin{tabular}{|c|c|c|c|}
\hline & \multicolumn{3}{|c|}{$\begin{array}{c}\text { Absence or presence of stubble or waxy areas } \\
\text { elsewhere in the colony }\end{array}$} \\
\hline & $\begin{array}{c}\text { Absent } \\
\text { (no.) }\end{array}$ & $\begin{array}{l}\text { Present } \\
\text { (no.) }\end{array}$ & $\begin{array}{l}\text { Percentage } \\
(\%)\end{array}$ \\
\hline \multicolumn{4}{|c|}{ Colonies with colour variations } \\
\hline Fluffy yellow area* & 24 & 11 & $\mathbf{3 2 \cdot 3}$ \\
\hline Stubble yellow area* & 50 & 44 & $46 \cdot 6$ \\
\hline Waxy yellow area* & 18 & 39 & $68 \cdot 4$ \\
\hline All colonies $†$ & 1318 & $\mathbf{3 5 4}$ & $\mathbf{2 1} \cdot \mathbf{2}$ \\
\hline
\end{tabular}

Unstable lines. A few of the variant types were stable on subculture, but the majority yielded spores which developed into a further range of variant colonies, reversions to a stable wild-type appearance being rare. Spores from the morphologically normal sectors of induced mutant colonies, and from crinkled areas, gave rise to mixtures of various 'mutant' types of growth (some of them occurring as sectors) and of morphologically normal (or nearly normal) colonies carrying the instability. These latter made up $15-75 \%$ of the total colonies, and spores from them grew in turn into a similar mixture of colony types, and so on. Thus certain of the unstable lines could be perpetuated indefinitely by serial substreaking from the spores of successive morphologically normal colonies. Such lines differed among themselves in the appearance of the various colony types and in the proportions of the different categories. Thus, of four unstable lines studied in detail, line 1 gave approximately $60 \%$ morphologically normal colonies at each transfer and line $2,20 \%$. The crinkled category was common in the streaks of lines 1 and 4, but rare in those of 2 and 3. Waxy was common in lines 2 and 3, and yellow (or white) waxy areas occurred with frequencies of about $10 \%$ in line 2 and $1 \%$ in line 3. All waxy types were rare in lines 1 and 4, but fluffy white areas occurred occasionally and were not seen in the other lines. The crinkled colonies from line 3 were minute except for 1 or $2 \%$ which were of normal size. (Pl. 1, fig. 6 shows the colonies which grew from spores of unstable line 2.)

Where substreaking was always from spores of successive morphologically normal (or nearly normal) colonies of precisely the same appearance, the proportions of the various colony types tended to remain the same; line 2, for example, showed no change over fifteen transfers. However, unstable lines which yielded new colony types, or altered proportions, were obtained by subculturing from colonies of a different appearance, and an apparently limitless collection of unstable lines could be derived by successive selections of different variants.

The absence of peripheral waxy sectors in the morphologically normal colonies of unstable line 2 is at first sight difficult to reconcile with the higher proportion of waxy spores from these colonies. However, at least two hypo- 
theses are possible: (1) nuclear instability might be limited to the times of spore germination and of spore formation (or formation of the aerial mycelium); or (2) genetically waxy nuclei might arise at a constant rate per nuclear division to produce a heterokaryon with a nearly normal phenotype. In the latter case mutations to waxy which occurred in the early nuclear divisions might result in waxy sectors, with later mutations contributing only to the heterokaryosis. It should be noted that with either of the above interpretations, high degrees of nuclear instability must be assumed.

Stable lines of some of the various 'mutant' types were found occasionally. Also, stable lines which were indistinguishable from the wild type, were obtained from certain rare colonies of line 2. As the usual 'morphologically normal' colonies of this line had aerial mycelium with a slightly stronger orange tint than the wild type, the few stable colonies could be distinguished. It is of interest that the return to normal stability was coupled in these cases with a return from a nearly normal tint of aerial mycelium to what was apparently the precise wild type. All changes seemed to occur in a stepwise manner, and a number of attempts to select for gradual shifts in the proportions of morphologically normal colonies failed. However, there was no predetermined sequence of changes; nor were the changes a matter of irretrievable loss of characters, since in the case of one of the stubble yellow lines a proportion of the spores developed into colonies of the normal colour (stubble orange and waxy orange).

Thus, the overall pattern of the instabilities appeared to be of almost limitless complexity, both the likelihood of further change and the directions which it could take differing in different lines and changing with each change in colony morphology; there appeared to be a limitless range of phenotypes. Occasionally variant colonies arose from untreated wild type spores, and these were indistinguishable from the induced variants and gave rise to similar unstable lines.

\section{Nature of the induced changes}

The initial changes in Streptomyces had two properties in common with those of many other organisms: they were induced by ultraviolet and ionizing radiations, and the ultraviolet dose/effect curve reached a peak followed by a decline (see Table 4). By analogy, these changes might be expected to be due to nuclear events, but they differed from the gene mutations of other organisms in that they were induced in much higher proportions, and that gamma irradiation was equally or more effective than was ultraviolet irradiation. This is the behaviour which might be expected if gross chromosomal rearrangements were predominant. Such an interpretation, in view of the apparent similarity between the initial induced changes and those which followed spontaneously, would follow from the fact now well established in at least one higher organism (see McClintock, 1951), that certain chromosomal rearrangements can cause a predisposition to further rearrangement (and perhaps to gene mutation). And, if one wishes to speculate further, McClintock's (1951, p. 43) suggestion, that alterations in heterochromatin could be 
responsible for the development of unstable lines in maize, might perhaps be applicable also to the present organism. No attempt will be made to discuss alternative interpretations, except to indicate that any which involve a segregation of pre-existing genetic particles as the sole cause would not seem

Table 4. Frequency of mutant colonies from irradiated and non-irradiated spore suspensions

\begin{tabular}{|c|c|c|c|}
\hline \multirow[b]{2}{*}{ Treatment } & \multirow{2}{*}{$\begin{array}{c}\text { No. colonies } \\
\text { examined }\end{array}$} & \multicolumn{2}{|c|}{ Mutant colonies } \\
\hline & & No. & $\%$ \\
\hline None (control) & 5507 & $\mathbf{2 9}$ & 0.5 \\
\hline $\begin{array}{l}\text { Gamma } 50,000 \mathrm{r} . \\
\text { Ultraviolet (ergs/sq.mm.) }\end{array}$ & 1672 & 514 & $30 \cdot 7$ \\
\hline 500 & 357 & 118 & B3.1 1 \\
\hline 1000 & 518 & 89 & $17 \cdot 2$ \\
\hline 2000 & 587 & 89 & $15 \cdot 2$ \\
\hline
\end{tabular}

Note. The above experiment is typical of many which have been carried out. In some the gamma irradiation produced approximately the same proportions of mutant colonies as the ultraviolet, and in others it resulted in as much as twice the proportion (up to $60 \%$ mutant colonies).

to account satisfactorily either for the onset of a supposed ability to segregate or for the apparently limitless variety of phenotypes. Unstable lines have, of course, been described in many organisms (for a recent and closely parallel case in Bacterium coli, described initially by Braun and Lewis, see Bryson, Prytz, Cuneo, Yongen \& Raymond, 1950), and the Streptomyces case may not be unique except in the ease with which the instabilities can be induced, and in the number of variant types which can be recognized.

I should like to acknowledge the technical assistance of Mr J. McGregor.

\section{REFERENCES}

Bryson, V., Prytz, B., Cuneo, H., Yongen, E. \& Raymond, C. (1950). Morphological and biochemical analysis of resistant bacteria. Annu. Rep. Biol. Lab. Cold Spring Harbor, no. 20.

KelNer, A. (1948). Mutation in Streptomyces flaveolus induced by X-rays and ultraviolet light. J. Bact. 56, 457.

Kelner, A. (1949). Studies on the genetics of antibiotic formation: the induction of antibiotic-forming mutants in Actinomycetes. J. Bact. 57, 73.

KLIENEberger-Nobel, E. (1947). The life cycle of sporing actinomyces as revealed by a study of their structure and septation. J. gen. Microbiol. 1, 22.

McClintock, B. (1951). Chromosome organization and genic expression. Cold Spr. Harb. Sym. quant. Biol. 16, 13.

Newcombe, H. B. (1951). Sectoring in colonies from irradiated cells of Escherichia coli. Genetics, 36, 570 .

Newcomвe, H. B. (1953). The delayed appearance of radiation induced genetic change in bacteria. Genetics, 38, 134.

WrtkIn, E. (1951a). Nuclear segregation and delayed expression of induced mutations in Escherichia coli. Genetics, 36, 583.

WrTkIN, E. (1951b). Nuclear segregation and delayed appearance of induced mutants in Escherichia coli. Cold Spr. Harb. Sym. quant. Biol. 16, 357. 


\section{EXPLANATION OF PLATE}

Figs. 1-5 are of colonies from irradiated spores.

Fig. 1. Three normal colonies (left); two wholly crinkled (right).

Fig. 2. A wholly stubble colony (except for central tuft of fluffy aerial mycelium) showing sectoring for different degrees of loss of aerial mycelium and different growth habits.

Fig. 3. A wholly waxy colony (left) showing a yellow sector at 1 o'clock, and a sector with slight colour change at 5 o'clock. A crinkled colony (right) with two large stubble sectors at 4 and 7 o'clock, and two small waxy sectors at 11 and 1 o'clock.

Fig. 4. A wholly crinkled colony (top). A sectored waxy colony (right), with morphologically normal sector.

Fig. 5. Two colonies of smaller size (minutes) (near top). Two crinkled colonies with stubble sectors (lower left and middle right).

Fig. 6. Streak from spores of unstable line number 2; light areas are fluffy (morphologically normal) and dark areas waxy.

(Received 15 December 1952) 
Journal of General Microbiology, Vol. 9, No. 1
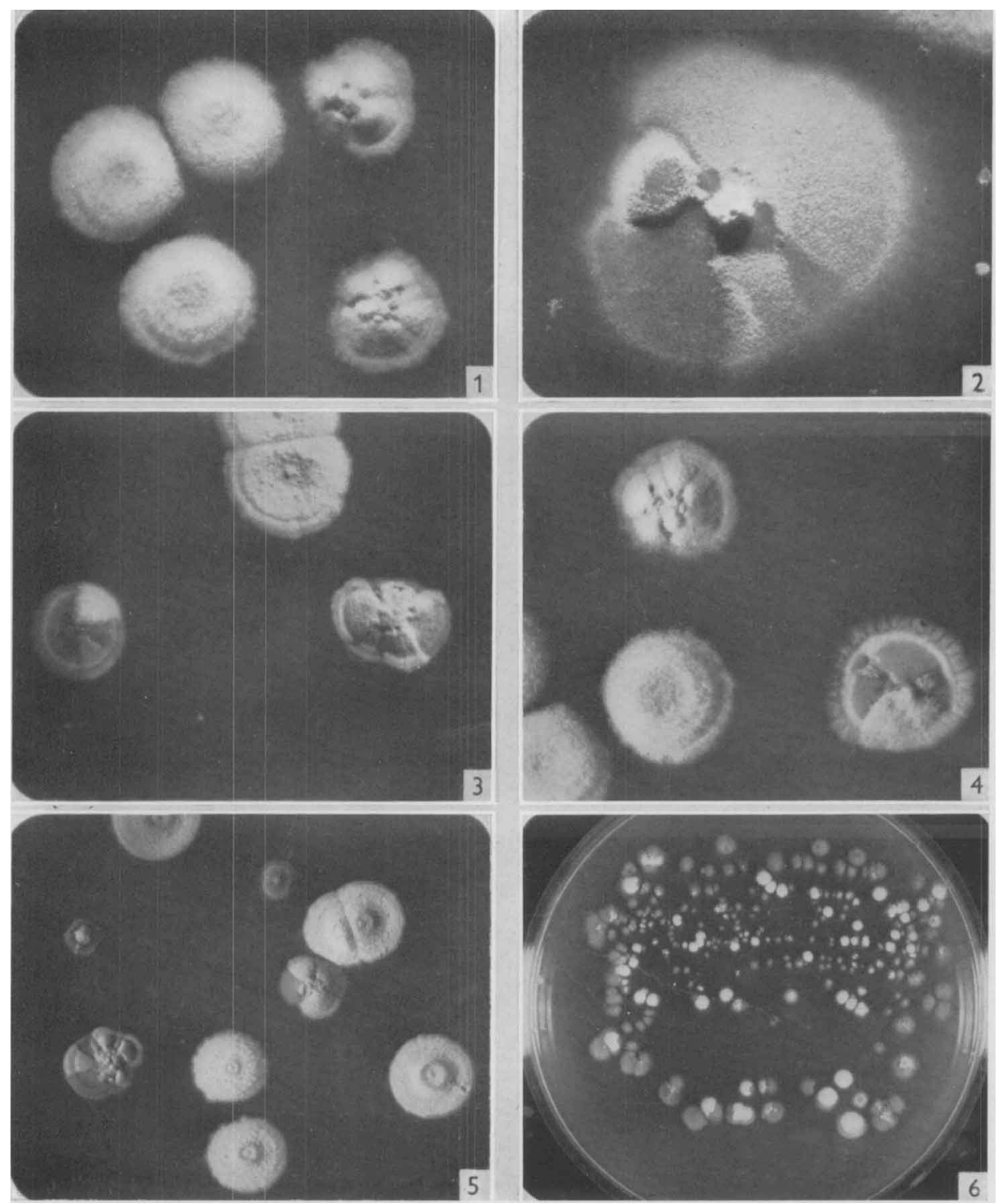

H. B. Newcombli-Instabilitils in S'Trep'romyclis. Plate 1 